\title{
Microstructural Study of a Nitroxide-Mediated Poly(Ethylene Oxide)/Polystyrene Block Copolymer (PEO-b-PS) by Electrospray Tandem Mass Spectrometry
}

\author{
Marion Girod, ${ }^{\text {a }}$ Trang N. T. Phan, ${ }^{\mathrm{b}}$ and Laurence Charles ${ }^{\mathrm{a}}$ \\ ${ }^{a}$ Laboratoire Chimie Provence, Spectrométries Appliquées à la Chimie Structurale, Universités Aix-Marseille \\ I, II and III-CNRS, UMR 6264, Marseille, France \\ ${ }^{\mathrm{b}}$ Laboratoire Chimie Provence, Chimie Radicalaire, Organique et Polymères de Spécialité, Universités \\ Aix-Marseille I, II and III-CNRS, UMR 6264, Marseille, France
}

Electrospray@onization@andem@nass@pectrometry@has@een@used@o@haracterize@he@nicrostructure@f@@itroxide-mediated@oly(ethylene@xide)/polystyrene@lock@opolymer,@alled SG1-cappedథEO-b-PS.बhe@nain@issociation@oute@\&o-oligomers@dducted@ithđithium@r silver@ation@as@bserved@o@roceed@ia@he@homolytic@leavage@f@@-ON@ond,@imed@t undergoing@eversible@homolysis@uring@itroxide@mediated@olymerization.CThis@leavage results@n@he@limination@f@he@erminal@sG1@nd-group@s@@adical,@nducing@@omplete


eliminations@f@tyrene@nolecules@llowed@@traightforward@etermination@f@he@S@lock size.CAn@alternative@fragmentation@pathway@of@the@radical@cation@was@shown@to@provide structural@nformation@n@hequnction@roup@etween@he@wo@blocks.@roposed@issociation mechanisms@ere@upported@y@ccurate@nass@neasurements. Structural@nformation@n@he

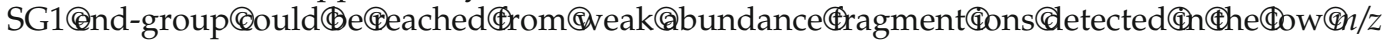
range@f(he@MS/MS@pectrum. Amongstథragments@ypically@xpected@romథS@issociation,

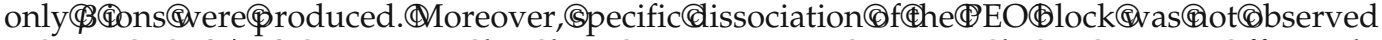
to@ccur@n@M/MS, (⿶uggesting@hat@hese@earrangement@eactions@o@ot@ompete@ffectively




2008,@9,@163-1175)@(2008@American(\$ocietyథfor@Mass@spectrometry

$\mathrm{B}$ lock@opolymers@have@become@@entral@omponent@f@umerous@anotechnologies@1]థecause of@heir@highly@rdered@ranostructures $\$ 2, \mathbb{O}] @$ and the@evelopment@f@esignథparadigms@4]@o@enerate nanostructures@of@particular@sizeCand@shape.@Unique properties@n@elective@olvents@an@be@btained@with amphiphilic@opolymers,@onsisting@f@ydrophilic@nd hydrophobic@arts.@opolymers@ontaining@oly(ethylene@xide)(PEO)@s(hydrophilic@egment@re@he@nost extensively@tudied@nd@ndustrially@ignificant@ue@o their@umerous@iological@nd@hemical@roperties $₫ 5]$. In@particular,@combinations@of@PEO@with@polystyrene (PS)@in@PS-b-PEO@diblock@or@PS- $b$-PEO- $b$-PS@triblock copolymers@are@used@in@many@industrial@applications such@s@olymeric@urfactants,@ompatibilizers@n@olymer(1) lending, बispersions, (atabilizers,@nd@emplatesథor theథreparation@f(norganic@anoparticles $\Phi 6-8]$. @Vovel applications Chave@recently@been@eveloped@using@he self-assembly@rdered@anostructures@f(ాEO-b-PS@nd

Address reprint requests to Dr. L. Charles, Spectrométries Appliquées à la Chimie Structurale, Campus Saint-Jérôme, Case 511, 13397 Marseille Cedex 20,®rance.థt-mail:@aurence.charles@univ-provence.fr
PS- $b$-PEO- $b$-PS, Ce.g., Cthe@preparation@of@mesoporous silica@ilms@ith@ifferentథore@izesథ9]@nd@lectrolyte for@echargeable $\$$ atteries $\Phi 10]$.

In@he@ast@ecade, (he@najor@breakthrough@n@lock copolymer@ynthesis@has@een@he@evelopment@f@ontrolled@radical@polymerization@(CRP)@echniques@11]. Moreథarticularly,@n@riginal@ethod@ased@n@itroxide@mediated@polymerization@(NMP)@allows@well@defined@tructure@opolymers@o@e@ynthesized@oth@n laboratory@nd@ndustrial@cale.CThe@rinciple@f@NMP technique@is@to@establish@a@dynamic@equilibrium@between@@mall@raction@f@rowing@ree@adicals@nd@ majority@@ormant@pecies@scheme@).đhe@eversible termination@f(he@rowing@olymeric@hains@s@he@rey

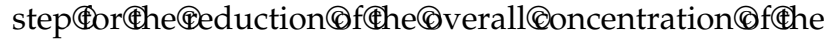
propagating@adical@hain@nd,@llowing@olymerization to occur in a living fashion with a high degree of control over the entire polymerization process.

The performance of copolymer materials depends on structurally related parameters, such as molecular weight distribution, chemical nature of the end-groups, random or block nature of copolymer, and balance between hydrophobic and hydrophilic segments. Un- 


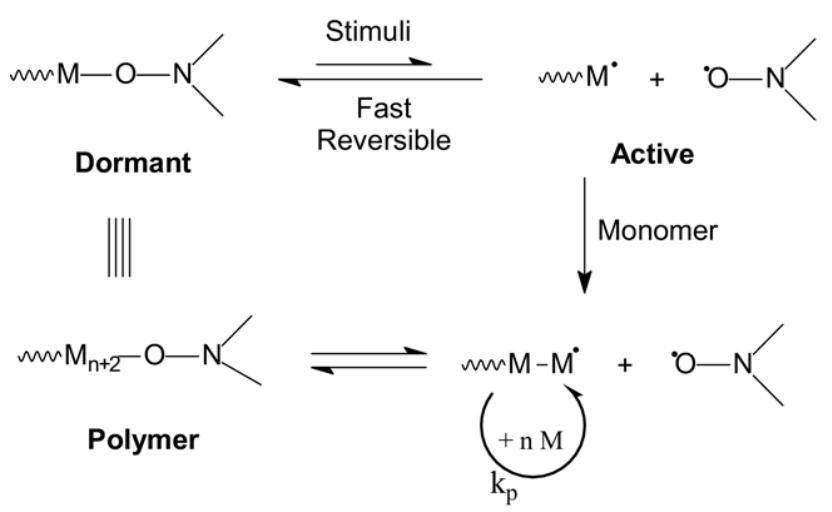

Scheme 1

ambiguous characterization of copolymer microstructure is thus an important analytical issue. Since the development of soft ionization techniques, mass spectrometry (MS) has been shown to be a powerful tool for copolymer analysis. MS spectra obtained after matrixassisted laser desorption/ionization (MALDI) or electrospray ionization (ESI) allow copolymer samples to be easily distinguished from homopolymers [12]. Since copolymers contain more than one type of repeat unit, MS spectra are significantly more complicated. However, as MS allows individual co-oligomer ions to be measured, the overall composition and mass of endgroups can be reached, as long as any peak overlap can efficiently be resolved [13]. Data from MS spectra could thus indicate the number of each co-monomer but not the position of the repeat units throughout the molecule. To distinguish block from random copolymers, ion fragmentation is required since fragmentation patterns are specific of a polymer type [12]. Alternatively, ion mobility was reported to provide useful information as long as cross-sections of copolymer differ upon variation in the co-monomer sequence [14]. Fragmentation can be produced in hard ionization sources [15] or after ions are activated in MS/MS or post-source decay (PSD) experiments. Copolyethers [16-20] and copolyesters $[13,21-24]$ have been the most studied synthetic copolymers in terms of fragmentation. A larger number of product ions are usually generated from copolymer than from homopolymer precursor ions [12]. However, some block copolymers have been reported to undergo selective fragmentation of a function between the two blocks, thus providing clear information about the block size from a simple PSD spectrum [17]. Electron capture dissociation has also been described to cause minimal rearrangement of copolymer ions, thus simplifying the fragment ion spectra while maintaining useful structural information [18]. Significant differences between product ion spectra enable differentiation between block and random copolymers [19]. First, although usually larger than for homopolymers, the number of fragment ions arising from dissociation of a block co-oligomer is smaller than for a random one because many more sequences are present in the latter
[12]. More importantly, fragmentation pathways along the chain allow the copolymer to be sequenced since each co-monomer shows distinct dissociation behavior. MS/MS or PSD data of copolymers can then be analyzed based on the knowledge of the fragmentation behavior of homopolymers consisting of each of the co-monomers.

We report here on a MS/MS study of poly(ethylene oxide)/polystyrene block copolymer (PEO-b-PS), synthesized by nitroxide-mediated polymerization (NMP) [25]. The main steps of this synthesis are described in Scheme 2. Such PEO- $b$-PS diblock copolymer with well defined structure has $\mathrm{CH}_{3}$ - as the $\alpha$ end-group, SG1 nitroxide as the $\omega$ end-group and a linkage group between the two blocks, as illustrated in Scheme 2. Fragmentation pathways of PEO oligomers have already been demonstrated, using fast atom bombardment (FAB) [16, 26], MALDI [27-32], ESI [33-35], or desorption electrospray ionization (DESI) [36] to generate oligomer adducts. Structural characterization of PS ions produced by MALDI has been reported using collision-induced dissociation (CID) [27, 37-42], sustained off-resonance irradiation (SORI)-CID [43], or PSD [39], and fragmentation pathways were described. These established dissociation routes were then used to reach structural information from CID spectra of the studied SG1-capped PEO-b-PS copolymer.

\section{Experimental}

\section{Chemicals}

Methanol and HPLC grade water were purchased from SDS (Peypin, France). Salts used to promote electrospray ionization were $\mathrm{LiCl}$ and $\mathrm{AgNO}_{3}$ from SigmaAldrich (St. Louis, MO).

All reaction steps for the preparation of SG1-capped PEO-b-PS (3) were performed under a dry nitrogen atmosphere. Poly(ethylene glycol) methyl ether (PEO-Me) with $M_{n}=350 \mathrm{~g} \mathrm{~mol}^{-1}$, styrene (99\%), acryloyl chloride (96\%) and triethylamine (TEA, 99\%) were all purchased from Sigma-Aldrich and were used as received without further purification. The $\mathrm{SG}_{1}$-based alkoxyamine derived from methacrylic acid, also called MAMA-SG1 (acid 2-methyl2-[N-tert-butyl-N-(1-diethoxyphosphoryl-2,2-dimethyl propyl)aminoxy] propanoic) was kindly supplied by ARKEMA. All solvents were used without any further purification.

\section{Copolymer Synthesis}

The synthetic procedure of (3) involves three steps: the preparation of PEO-acrylate (1), the intermolecular radical addition of MAMA-SG1 alkoxyamine onto (1) and the polymerization of styrene using PEO-acrylateMAMA-SG1 (2) as an initiator (Scheme 2). PEO-acrylate (1) was obtained by esterification of PEO-Me $\left(M_{n}=\right.$ 350 g. $\mathrm{mol}^{-1}$ ) with an acryloyl chloride. One of the vinyl protons of the acrylate group in (1) could be observed 



PEO-acrylate-MAMA-SG1 (2)



Scheme 2

by ${ }^{1} \mathrm{H}$ NMR at $\delta=6.40-6.45 \mathrm{ppm}$. The reaction yield of this first step (95\%) was determined by comparing the integration of this proton peak and the $\mathrm{CH}_{3} \alpha$-endgroup protons $(\delta=3.38 \mathrm{ppm})$. Addition of the MAMASG1 alkoxyamine to the PEO-acrylate (1) occurs via a thermal homolysis of the C-ON bond leading to the formation of the two radicals: the transitory alkyl radical MAMA and the stable SG1 nitroxide. Because of the high dissociation rate constant of the MAMA-SG1 alkoxyamine [44] a high concentration of SG1 is released at the onset of the reaction. The persistent radical effect [45] is then strongly pronounced, and neither oligomerization nor dimerization is expected. The presence of activated olefin (1) leads to an intermolecular radical 1,2-addition. The ${ }^{1} \mathrm{H}$ NMR spectrum of the PEO-acrylate-MAMA-SG1 shows that the signals due to the vinyl protons of the acrylate group $(\delta=5.75-6.45$ ppm) disappear, indicating a $100 \%$ yield for this addition reaction. The PEO-acrylate-MAMA-SG1 (2) was then used to initiate the bulk polymerization of styrene at $105^{\circ} \mathrm{C}$ for 150 min under inert atmosphere. The styrene/PEO-acrylate-MAMA-SG1 concentration ratio was such that a theoretical PS molar mass of $1700 \mathrm{~g}$ $\mathrm{mol}^{-1}$ at $100 \%$ conversion was expected. The polymer- ization was stopped by quenching the reaction in an ice bath. The SG1-capped PEO- $b$-PS diblock copolymer was precipitated in cold $n$-hexane, rinsed with diethyl ether and dried under vacuum at room temperature. Styrene conversion was determined by ${ }^{1} \mathrm{H}$ NMR spectroscopy (conversion $=26.5 \%$, expected $M_{n}(\mathrm{PS})=400 \mathrm{~g} \mathrm{~mol}^{-1}$ ). The ${ }^{1} \mathrm{H}$ NMR spectrum of the final PEO- $b$-PS copolymer in $\mathrm{CDCl}_{3}$ shows new peaks $(\delta=6.5-7.2 \mathrm{ppm})$ corresponding to the phenyl protons of the PS block. This confirms the formation of the block copolymer as schematized in Scheme 2. The final copolymer composition was thus determined from the ratio between the integrals of the PS phenyl ${ }^{1} \mathrm{H}$ signals and the methyl ${ }^{1} \mathrm{H}$ signal of the $\alpha$-end-group. Considering the molar mass values given by supplier for the PEO block $\left(M_{n}=350 \mathrm{~g}\right.$ $\mathrm{mol}^{-1}$ ), the ${ }^{1} \mathrm{H}$ NMR compositional analysis indicated a PS block molar mass of $300 \mathrm{~g} \mathrm{~mol}^{-1}$.

\section{Mass Spectrometry}

MS and MS/MS experiments were performed with a QStar Elite mass spectrometer (Applied Biosystems SCIEX, Concord, ON, Canada) equipped with an electrospray ionization source operated in the positive ion 
mode. The capillary voltage was set at $5500 \mathrm{~V}$ and the cone voltage at $80 \mathrm{~V}$. In this hybrid instrument, ions were measured using an orthogonal acceleration time-of-flight (TOF) mass analyzer. A quadrupole was used for selection of precursor ions to be further submitted to collisioninduced dissociations (CID) in MS/MS experiments.

$\mathrm{MS}^{3}$ experiments were performed with a $3200 \mathrm{Q}-$ TRAP mass spectrometer (Applied Biosystems SCIEX) equipped with an electrospray ionization source operated in positive mode. The capillary voltage was set at $4500 \mathrm{~V}$ and the cone voltage at $80 \mathrm{~V}$. Primary precursor ions generated in the ion source were selected in the quadrupole analyzer and submitted to CID in a collision cell. Secondary precursor ions produced during collisions were selected and then fragmented in a linear ion trap.

In both instruments, zero-grade air was used as the nebulizing gas (10 psi) whereas nitrogen was used as the curtain gas (20 psi) as well as the collision gas. Collision energy was set according to the experiments. Instrument control, data acquisition and data processing of all experiments were achieved using Analyst software (QS 2.0 and 1.4.1 for the QqTOF and the QqTrap instruments, respectively) provided by Applied Biosystems.

The SG1-capped PEO- $b$-PS copolymer was dissolved in THF, further diluted using methanolic salt solution (0.1 $\mathrm{mM}$ ) to a final $1 \mathrm{mg} \mathrm{mL}^{-1}$ concentration and introduced in the ionization source at a $5 \mu \mathrm{L} / \mathrm{min}$ flow rate using a syringe pump.

\section{Results and Discussion}

\section{ESI-MS Analysis}

ESI mass spectra of SG1-capped PEO- $b$-PS could be obtained using lithium or silver salt to generate copolymer adducts. The choice of these two particular cations was based upon the nature of the co-monomers. MS/MS spectra of lithiated PEO precursors were reported to be the most informative [16, 26, 30-32, 46], while characterization of PS oligomer systems is usually performed with silver cation. Using lithium as the cationizing agent, ions observed in the mass spectrum were mostly singly charged molecules. Doubly charged co-oligomers were detected with a 10 time lower intensity compared with their singly charged homologues. A small copolymer was chosen for this study to prevent the formation of ions with multiple charge states, so readily obtained during ESI of moderate size PEO [47], which would both complicate the MS spectrum and affect signal-to-noise ratio since signal of each molecule would be distributed over multiple peaks. Figure 1 shows the ESI mass spectrum of lithiated SG1-capped PEO- $b$-PS copolymer. Within the displayed $m / z$ range where singly charged ions were observed, homologue



Figure 1. ESI-MS spectrum of SG1-capped PEO- $b$-PS block copolymer using lithium as the cationizing agent. Most intense peaks are annotated as $n, m$, where $n$ and $m$ are the number of ethylene oxide and styrene units in the co-oligomer ion, respectively. 
Table 1. Detected $m / z$ values of lithiated SG1-capped PEO- $b$-PS co-oligomer ions

\begin{tabular}{|c|c|c|c|c|c|c|c|c|}
\hline \multirow[b]{2}{*}{$\mathrm{n}^{*}$} & \multicolumn{8}{|c|}{$\mathrm{m}^{*}$} \\
\hline & 1 & 2 & 3 & 4 & 5 & 6 & 7 & 8 \\
\hline 1 & & & 830.5 & & & & & \\
\hline 2 & & 770.4 & 874.5 & 978.6 & & & & \\
\hline 3 & & 814.5 & 918.5 & 1022.6 & 1126.6 & & & \\
\hline 4 & 754.4 & 858.5 & 962.6 & 1066.6 & 1170.7 & 1274.7 & & \\
\hline 5 & 798.5 & 902.5 & 1006.6 & 1110.6 & 1214.7 & 1318.8 & 1422.8 & \\
\hline 6 & 842.5 & 946.6 & 1050.6 & 1154.7 & 1258.7 & 1362.8 & 1466.8 & \\
\hline 7 & 886.5 & 990.6 & 1094.6 & 1198.7 & 1302.7 & 1406.8 & 1510.9 & 1614.9 \\
\hline 8 & 930.5 & 1034.6 & 1138.7 & 1242.7 & 1346.8 & 1450.8 & 1554.9 & 1658.9 \\
\hline 9 & 974.6 & 1078.6 & 1182.7 & 1286.7 & 1390.8 & 1494.9 & 1598.9 & \\
\hline 10 & 1018.6 & 1122.7 & 1226.7 & 1330.8 & 1434.8 & 1538.9 & & \\
\hline 11 & 1062.6 & 1166.7 & 1270.7 & 1374.8 & 1478.9 & 1582.9 & & \\
\hline 12 & & 1210.7 & 1314.8 & 1418.8 & 1522.9 & & & \\
\hline 13 & & 1254.7 & 1358.8 & 1462.8 & & & & \\
\hline 14 & & 1298.8 & 1402.8 & & & & & \\
\hline 15 & & & 1446.9 & & & & & \\
\hline
\end{tabular}

${ }^{*} \mathrm{n}$ and $\mathrm{m}$ indicate the number of ethylene oxide and styrene units, respectively.

series could be defined from each peak by adding or subtracting 44 or $104 \mathrm{Da}$, i.e., the mass of ethylene oxide and styrene unit, respectively. As the molecular weight of both end- and block linkage-groups are known, monomer composition of each ion could be calculated and is reported as n, $\mathrm{m}$ in Figure 1, where $\mathrm{n}$ and $\mathrm{m}$ are the number of ethylene oxide and styrene monomers, respectively. Only most intense peaks have been annotated for better clarity. Due to the small size of the copolymer and the respective mass of each co-monomer, no peak overlap was to be deplored and resolution provided by the orthogonal acceleration time of flight (oa-TOF) mass analyzer was sufficient to propose unambiguous composition for all detected ions. The $\mathrm{m} / \mathrm{z}$ values of lithiated copolymer molecules are reported in Table 1 (using $m / z=44 n+104 m+467+7$ ). These data are consistent with the indicated polymerization degree of the two blocks, as determined by ${ }^{1} \mathrm{H}$ NMR.

Using silver as a cationizing agent, the same $\mathrm{n}, \mathrm{m}$ co-oligomers could be detected. It should be noted, however, that ions were of much lower abundance compared with lithiated molecules.



Figure 2. ESI-MS/MS spectrum of lithiated SG1-capped $\mathrm{PEO}_{7}-b-\mathrm{PS}_{4}$ co-oligomer at $\mathrm{m} / \mathrm{z} 1198.7$ (collision energy: $30 \mathrm{eV}$, laboratory frame). 
Tandem Mass Spectrometry of Lithiated SG1-Capped PEO-b-PS

Collision-induced dissociation of lithium and silver adducts of the copolymer was performed. As the same main fragments were observed from both types of adduct and since higher intensity signal was obtained using $\mathrm{Li}^{+}$cation, fragmentation pathways are described in details for lithiated molecules. Any effect observed in MS/MS spectra to be due to silver cation has also been reported.

MS/MS experiments were performed on different co-oligomer ions and observed CID patterns were studied with regard to the expected ionic structure. The CID spectrum of $\left[7,4+\mathrm{Li}^{+}\right.$(Figure 2) was chosen to illustrate the MS/MS behavior of the studied copolymer as this precursor ion possesses blocks of large enough size to allow all the observed fragmentation pathways to be described while being of relatively high abundance to ensure a good quality of MS/MS data. Dissociation of this $m / z 1198.7$ precursor ion gave rise to an unexpectedly simple spectrum where only three main series could be observed. Indeed, a more complex MS/MS spectra was expected since, following Lattimer's pioneering work [16, 26], all CID studies of PEO homopolymers have described four main fragment ion series [27-31, 33-36], and Jackson [27, 37, 38] and others [39-42] have reported nine fragment ion series arising from dissociation of PS oligomer ions.

The first reaction, yielding an intense peak at $\mathrm{m} / \mathrm{z}$ 904.5 , would consist of a very fast homolytic bond cleavage, producing the release of SG1 as a nitroxide moiety from the precursor ion. This mechanism is supported by accurate mass measurement (904.5307, error: $6.0 \mathrm{ppm}$ ) and is described in Scheme 3. The release of this radical moiety during dissociation of the copolymer cationic adducts would be one of the numerous exceptions to the even-electron rule [48]. However, formation of odd-electron ions from electrosprayed cations was shown to be favored when the leaving group was strongly electro-negative [49]. The thermal instability of the $\mathrm{C}-\mathrm{ON}$ bond between the last styrene unit and the SG1 $\omega$-end-group in the studied PEO- $b$-PS is the basis of the NMP process (Scheme 1). The same homolytic cleavage would then occur upon collisional activation, as reported by Polce et al. [42] in a recent MS/MS study of PS homopolymers containing a labile substituent at a chain end. The so-obtained $\mathrm{m} / \mathrm{z} 904.5$ fragment ion has the same structure as B ions described by Jackson et al. [37, 38]. However, to avoid any confusion with capital letters used in the nomenclature proposed by Lattimer to describe PEO fragment ions $[16,26]$, Jackson's nomenclature for PS was used here with lower case letters. As a result, $\mathrm{m} / \mathrm{z} 904.5$ was named $b_{7,4}$, numbers in subscript indicating the composition in ethylene oxide and styrene units, respectively. The complementary [SG1 $+\mathrm{Li}^{+}$ion was observed at $\mathrm{m} / \mathrm{z} 301.2$ in the MS/MS spectrum. Relative intensity of peaks at $\mathrm{m} / \mathrm{z} 301.2$ and $\mathrm{m} / \mathrm{z} 904.5$ suggests that lithium

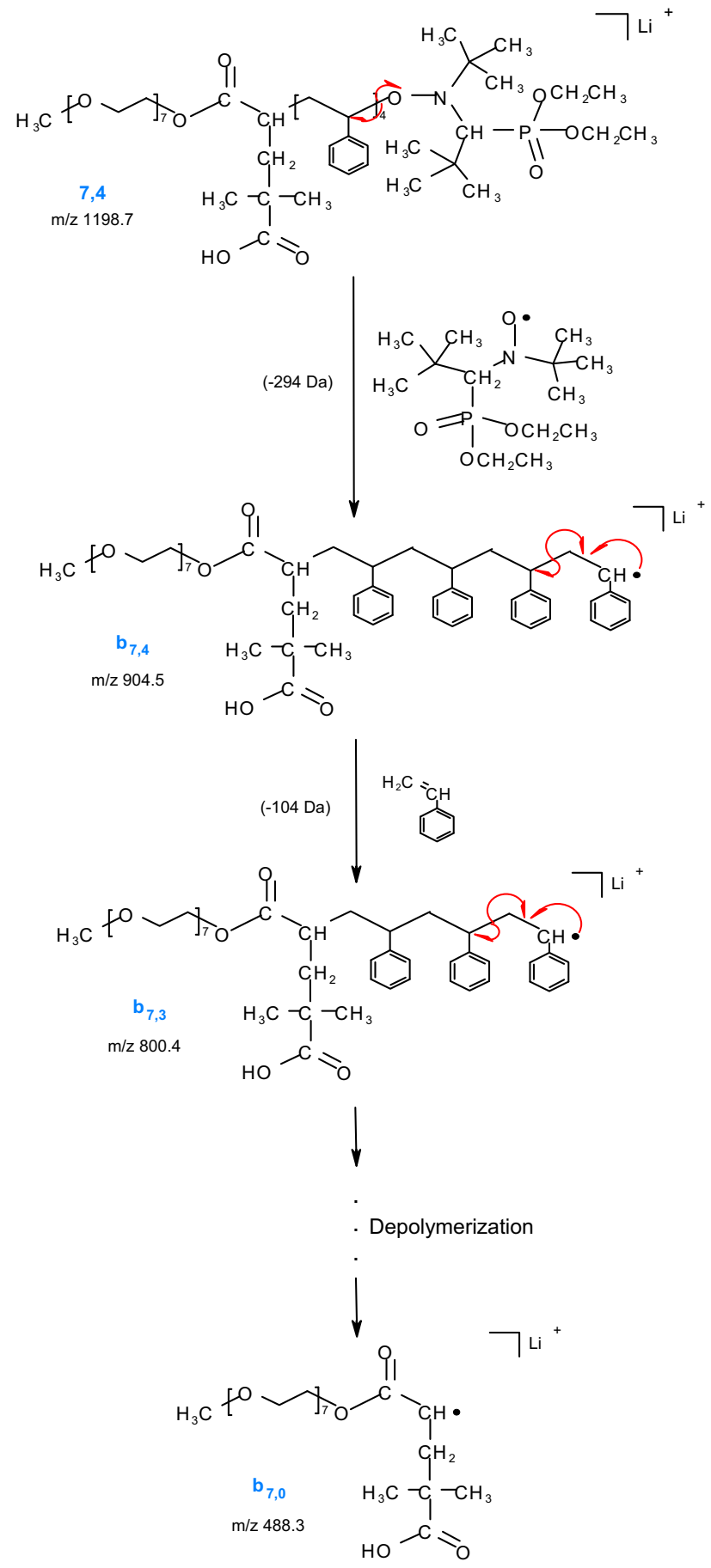

Scheme 3

cation would be more probably linked to the PEO chain than to the SG1 end-group. This result is consistent with data reported [35, 50-52], which show that stable conformation of lithiated PEO is obtained when the cation is buried deep in the oligomer chain and coordinated to as many oxygen atoms as possible.

The $b_{7,4}$ radical cation further dissociates, inducing a depolymerization process by radical $\beta$-scission (Scheme 3 ), consisting of successive eliminations of a styrene molecule (104 Da). This process gives rise to the following MS/MS 
filiation: $b_{7,4}(m / z$ 904.5 $) \rightarrow b_{7,3}(m / z$ 800.4 $) \rightarrow b_{7,2}(m / z$ $696.4) \rightarrow b_{7,1}(m / z 592.3) \rightarrow b_{7,0}(m / z$ 488.3). The number of $104 \mathrm{Da}$ neutral losses indicates the size of the PS block, as observed during CID of any of the studied co-oligomer precursor ions. These results also imply that the SG1 end-group was initially linked to the last styrene unit. This mechanism contradicts the PS fragmentation mechanism proposed by Gies et al. [40] who postulated multiple chain breaks and excluded consecutive monomer losses. On the other hand, the dissociation series shown in Scheme 3 agrees well with the mechanism recently reported by Polce et al. [41, 42], which includes styrene monomer losses from the radical ions formed after homolytic cleavages in the PS chain. Relative abundance of ions in this series is consistent with the proposed multiple step process: $b_{7, m}$ peak intensity decreases with the number of styrene units. The unexpected higher stability observed for $b_{7,1}$ might be explained by a possible delocalization of the unpaired electron onto the carbonyl oxygen atom via the formation of a six-membered ring. Alternatively, $b_{7,1}$ fragment ion could also directly arise from $b_{7,4}$ dissociation via a backbiting rearrangement (such a $1,5-\mathrm{H}^{\cdot}$ transfer is thermodynamically $[53,54]$ and kinetically [53] favored) followed by a radical-induced bond cleavage [41, 42].

An alternative fragmentation pathway of the $b_{7,4}$ radical cation should also be envisaged. Accurate mass measurement of the ion detected at $\mathrm{m} / \mathrm{z} 817.4$ (817.4861, error: $10.7 \mathrm{ppm}$ ) indicates the loss of a $\mathrm{C}_{4} \mathrm{H}_{7} \mathrm{O}_{2}$ moiety



Scheme 4 
from $m / z$ 904.5, suggesting the elimination of the MAMA group as a radical. To account for the formation of this $\left[\mathrm{b}_{7,4}\right.$-MAMA] cation, the proposed mechanism would consist of a three-step pathway (Scheme 4). Two consecutive 1,5-transfers of $\mathrm{H}^{\prime}$ would first occur and the subsequent release of MAMA would proceed via a radical $\beta$-scission process [40-42]. This mechanism suggests that all $b_{7, m}$ fragment ions should eliminate a MAMA radical in a similar way. However, the number of rearrangement steps involving $\mathrm{H}$ transfers would depend on the length of the PS block in each $b_{7, m}$ radical cation. Moreover, whereas the reaction would mainly proceed via 1,5-transfers of $\mathrm{H}^{\cdot}$ when $\mathrm{m}$ is an even number, an additional 1,3-transfer (such as previously reported in PS fragmentation [40]) has to be envisaged to allow the final release of MAMA when the fragment- ing species contains an odd number of styrene units. Accurate mass measurement of ions at $m / z$ 713.4, 609.3, 505.3 , and 401.2 supports these hypotheses and allow the corresponding peaks to be annotated $\left[b_{7, m}-\right.$ MAMA] in Figure 2. It should be noted that, when using silver as the cationizing agent, $\left[b_{7, m}-M A M A\right]$ ions containing an odd number of styrene units were not detected in MS/MS. MS ${ }^{3}$ experiments, in which $b_{7, m}$ silver adducts were collisionally activated, were required to observe the expected release of MAMA: This result suggests that the 1,3-hydrogen transfer is a minor pathway for silver adduct dissociation, as previously reported by Gies et al. [40]. The 104 Da spacing measured between ions in this series could have suggested that $\left[b_{7, m-1^{-}}\right.$ MAMA] would alternatively result from the elimination of a styrene neutral from $\left[b_{7, m}\right.$-MAMA]. However,

(a)

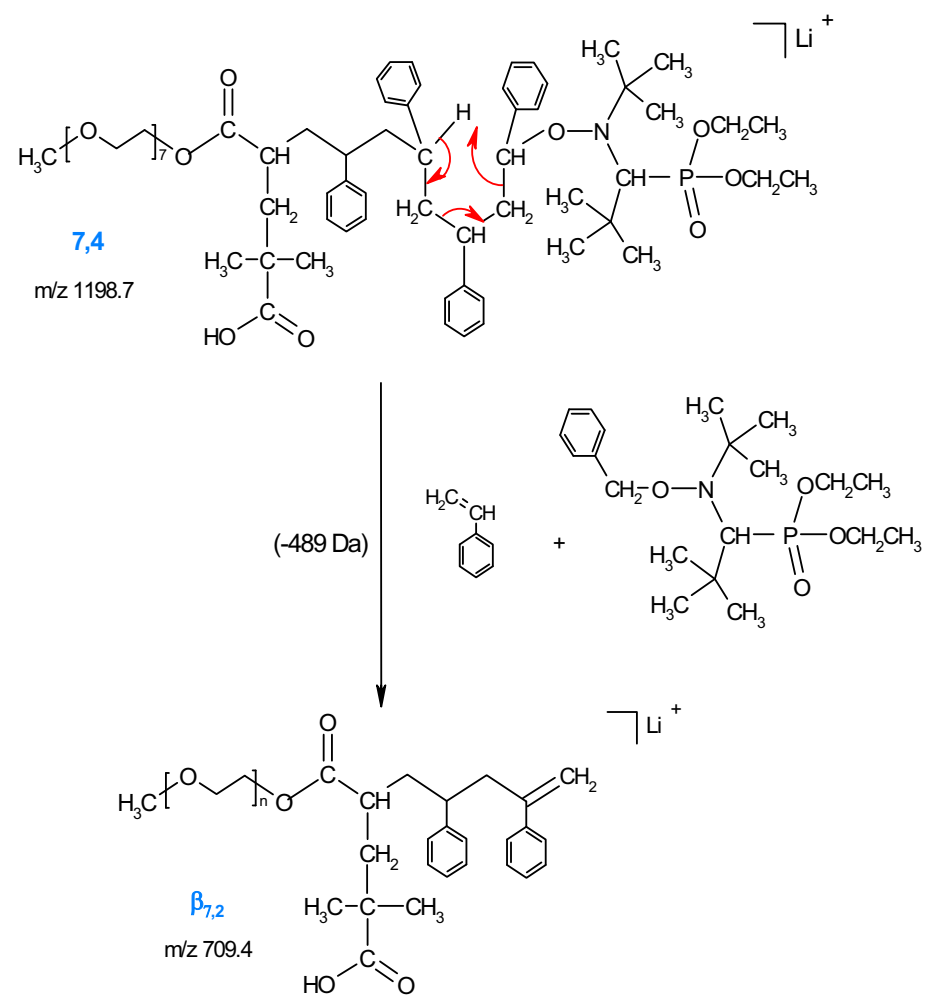

(b)

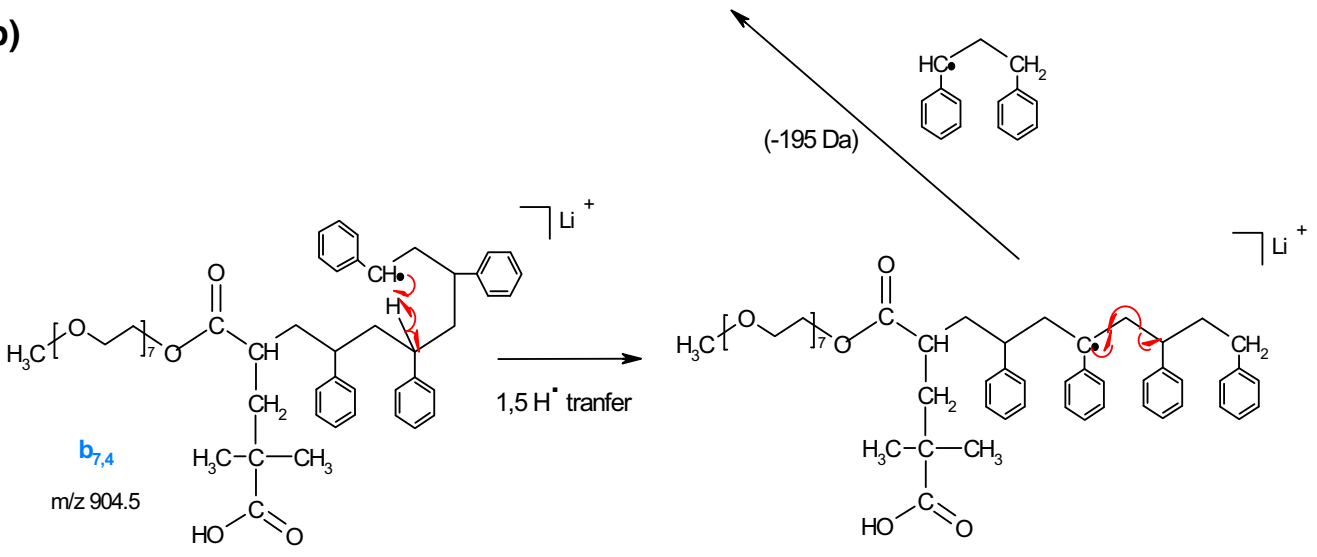

Scheme 5 




Scheme 6

$\mathrm{MS}^{3}$ experiments have shown that such a MS/MS filiation did not exist. In contrast, dissociation of all $\left[b_{7, m}-M A M A\right]$ was observed to yield the $\left[b_{7,0}-M A M A\right]$, indicating the loss of a neutral molecule containing $\mathrm{m}$ styrene units. This reaction would proceed via a 1,5proton transfer to the $\mathrm{O}$ atom, as described in Scheme 4.

(a)<smiles>C=CC(=O)OCCOC(C)C</smiles>

(b)

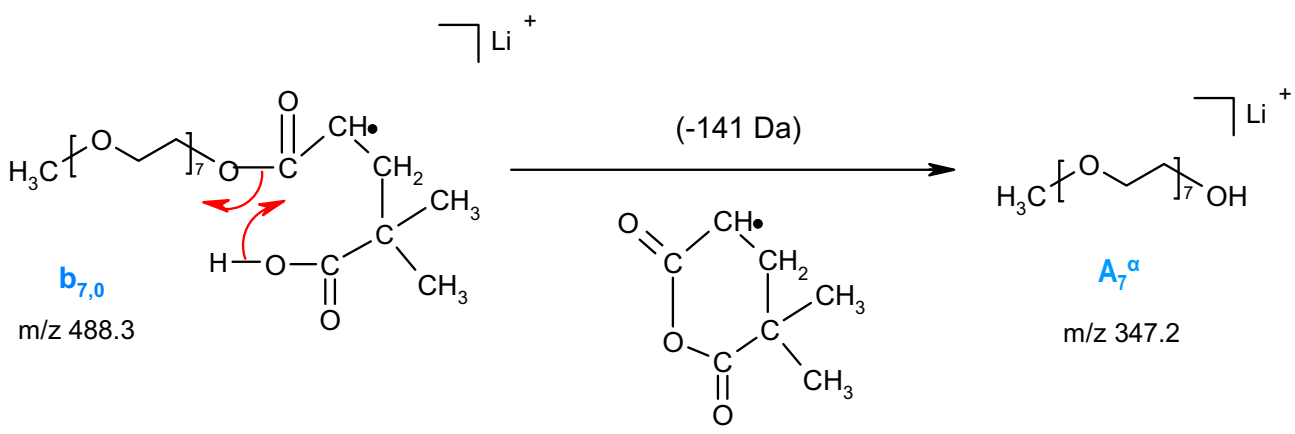


This result would account for the higher intensity of $\left[b_{7,0}-M A M A\right]$, as compared to the other ions within this series. No complementary ion could be detected, indicating that the position of the cation on the co-oligomer backbone was preferentially the PEO segment at the time of dissociation.

Peaks observed at $\mathrm{m} / \mathrm{z} 709.3, \mathrm{~m} / \mathrm{z} 605.3$, and $\mathrm{m} / \mathrm{z} 501.3$ in Figure 2 could be attributed to the PS specific $\beta$ fragments, and were respectively annotated $\beta_{7,2}, \beta_{7,1}$, and $\beta_{7,0}$. According to Jackson $[37,38]$, the mechanism would proceed via a six-member ring rearrangement within the PS block of the $[7,4+\mathrm{Li}]^{+}$precursor ion (Scheme 5a), allowing three species to be produced. In our case, only the species containing the PEO block was detected, indicating again the preferential location of $\mathrm{Li}^{+}$. However, the reaction depicted in Scheme 5a involves a proton transfer to a saturated carbon atom and has recently been questioned [41]. Alternatively, the same $\beta_{7, \mathrm{i}}$ ions could arise from the dissociation of $b_{7, i+2}$, as described in Scheme $5 \mathbf{b}$. In this mechanism, a 1,5-transfer of $\mathrm{H}^{-}$would produce a lithiated intermediate from which a $\beta$-scission would allow a 1,3- diphenylpropanyl radical to be released [40-42]. Scheme $\mathbf{6}$ summarizes the fragmentation pathways producing the main ions detected in Figure 2.

Additional peaks were detected in the low $\mathrm{m} / \mathrm{z}$ range of the MS/MS spectrum and mechanisms proposed to account for these weak abundance ions were based on accurate mass measurements. The ion detected at $\mathrm{m} / \mathrm{z}$ 329.2 would arise from the dissociation of $\left[b_{7,0}-\right.$ MAMA $]$, as described in Scheme 7a. This mechanism would involve a 1,5-proton transfer between a $\mathrm{C}$ atom from the last ethylene oxide unit to the central $\mathrm{C}$ atom of the allenic group, allowing a lithiated vinyl-terminated PEO oligomer and an acrylic acid neutral to be produced. The ion detected at $\mathrm{m} / \mathrm{z} 347.2$ would result from the dissociation of $b_{7,0}$. The acidic proton of the MAMA group would be transferred to the $\mathrm{O}$ atom of the ester function, yielding a lithiated hydroxyl-terminated PEO oligomer $(\mathrm{m} / \mathrm{z}$ 347.2) after elimination of a $141 \mathrm{Da}$ radical (Scheme $7 \mathbf{b}$ ). Based on their structure, these two ions were named $\mathrm{B}_{6}{ }^{\alpha}$ and $\mathrm{A}_{7}{ }^{\alpha}$, respectively, according to Lattimer's nomenclature $[16,26]$.

\section{(a)}

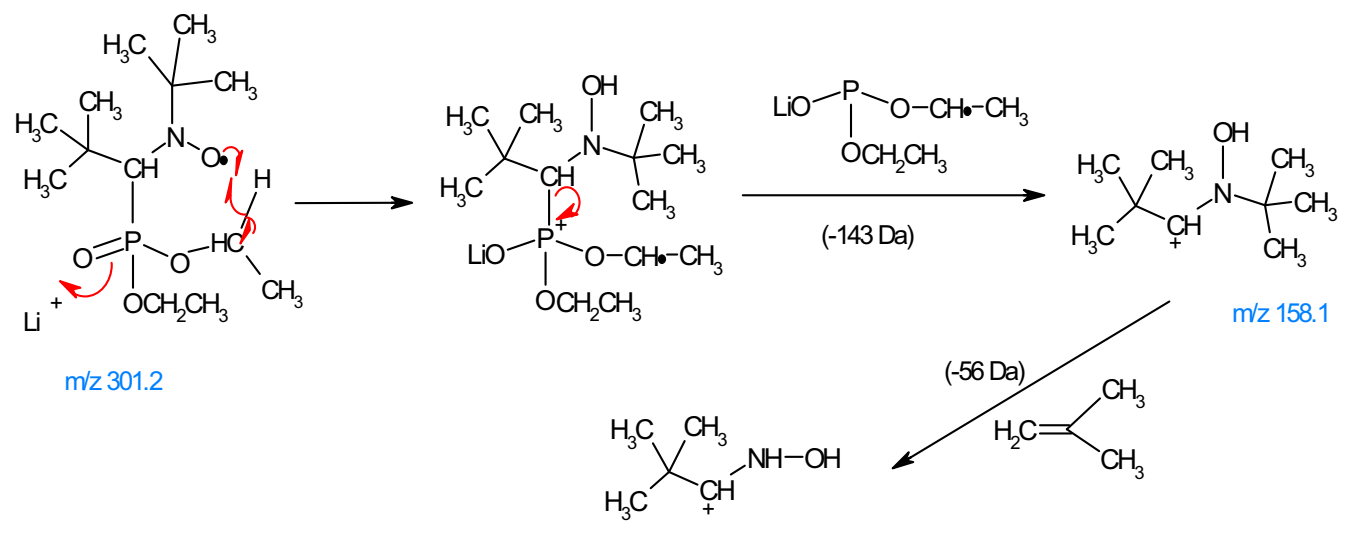

(b)

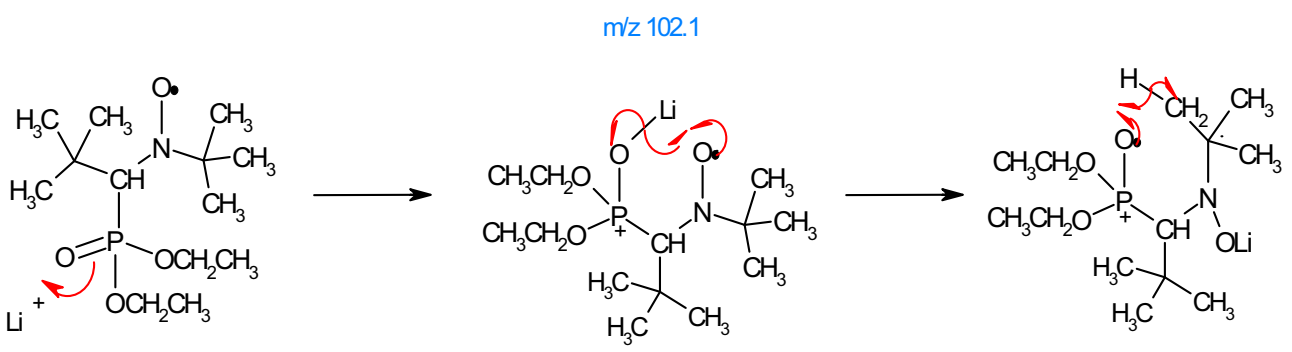

$\mathrm{m} / \mathrm{z} 301.2$
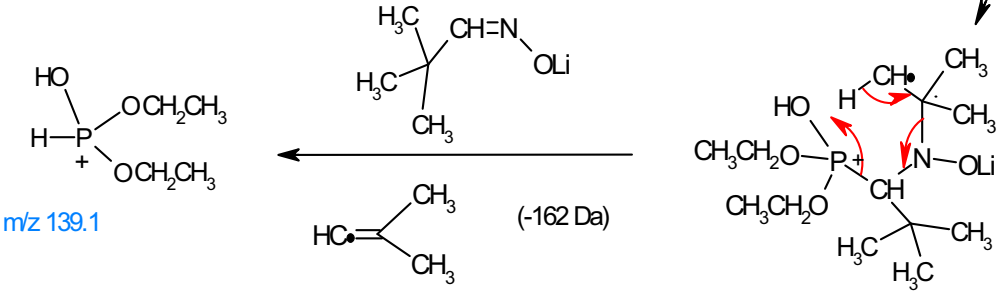

Scheme 8 


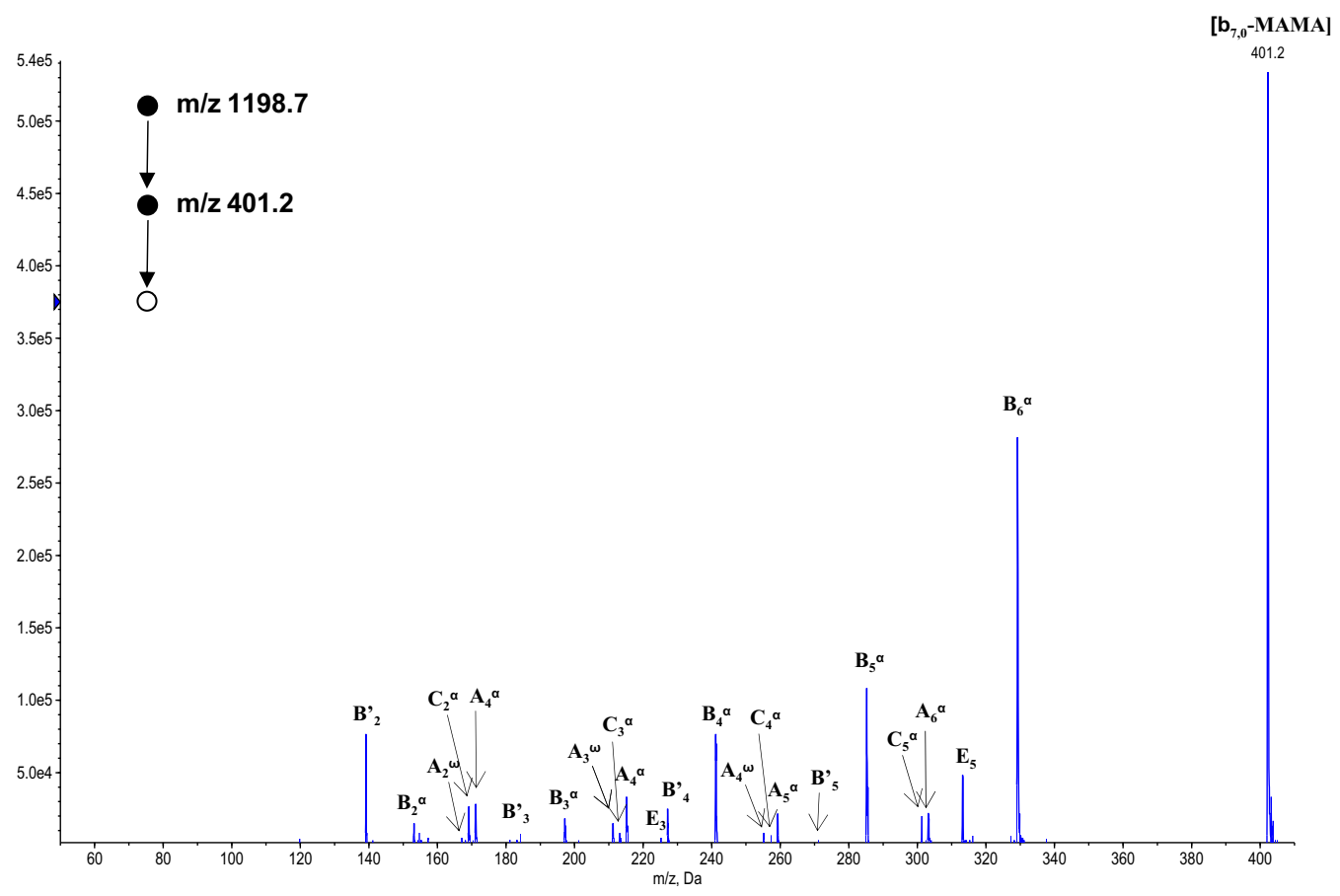

Figure 3. $\mathrm{MS}^{3}$ spectrum of $\mathrm{b}_{7,4} \rightarrow\left[\mathrm{b}_{7,0}\right.$-MAMA $] \rightarrow$ fragment ions. Collision energy was $30 \mathrm{eV}$ (laboratory frame) for the first dissociation step and excitation energy was set as AF2 = 100 for the second dissociation step.

Ions detected at $m / z$ 158.1, 139.1, and 102.1 were all proposed to arise from the dissociation of $\mathrm{m} / \mathrm{z}$ 301.1, previously identified as $\left[\mathrm{SG} 1^{-}+\mathrm{Li}^{+}\right.$. According to accurate mass values, these three ions do not contain the lithium atom, indicating that $\mathrm{Li}$ was eliminated in nonionic species. According to Scheme $8 \mathrm{a}, \mathrm{a} \mathrm{Li}-\mathrm{O}$ bond would be created, involving the $\mathrm{O}$ atom from the phosphonate group while a transfer of $\mathrm{H}^{-}$would occur from a $\mathrm{C}$ atom of an ethyl group to the nitroxide $\mathrm{O}$. Further reduction of the phosphorus oxidation state would allow the $\mathrm{m} / \mathrm{z} 158.2$ fragment to be produced. This ion would consecutively eliminate an isobutene molecule to yield $\mathrm{m} / \mathrm{z}$ 102.1. The mechanism proposed for the formation of $\mathrm{m} / \mathrm{z} 139.1$ would also involve the creation of a Li-O bond (Scheme $\mathbf{8 b}$ ). Two successive radical transfers, namely $\mathrm{Li}$ and $\mathrm{H}$, would then be required to allow the $\mathrm{m} / \mathrm{z} 139.1$ phosphonium ion to be produced. Although of very weak abundance, these three fragment ions provide structural information on the SG1 end-group.

It should be noted that although collision energy was increased (up to $110 \mathrm{eV}$, laboratory frame), no fragmentation was observed from the PEO block. The absence of dissociations within the PEO block could result from the fact that the $\mathrm{C}-\mathrm{C}$ and $\mathrm{C}-\mathrm{O}$ bonds in the PEO chain are stronger than the $\mathrm{C}-\mathrm{C}(\mathrm{Ph})$ bonds in the PS chain. Moreover, all mechanisms involved in cationized PEO fragmentation consist of rearrangement reactions [16, 26] and, as such, would not compete effectively with dissociations of the $b_{7, n}$ odd-electron ions. Specific PEO fragments could only be observed in $\mathrm{MS}^{3}$ experiments, from $\left[b_{7,0}-\right.$ MAMA] dissociation (Figure 3 ). All peaks in the $\mathrm{MS}^{3}$ spectrum could have been accounted for according to mechanisms established for PEO dissociation $[16,26]$ and using a slightly modified nomenclature [35]. The dissociation reactions would thus only be briefly described here. Lithiated hydroxyl terminated PEO $(n=3-6)$, named $\mathrm{A}_{\mathrm{n}}{ }^{\alpha}$ since the $\alpha$-end-group is retained, were produced during a charge-induced reaction. Charge-remote mechanisms would produce vinylterminated $\mathrm{B}_{\mathrm{n}}{ }^{\alpha}(n=2-6)$ and formyl-terminated $\mathrm{C}_{\mathrm{n}}{ }^{\alpha}$ $(n=2-5)$ ions, as well as their complementary $\mathrm{A}_{\mathrm{n}}{ }^{\omega}(n=$ 2-4) ions. Internal elimination of a dioxane molecule would produce $E_{5}$ from $\left[b_{7,0}-M A M A\right]$, as well as $E_{3}$ from $\mathrm{E}_{5}$. Fragment ions named here $\mathrm{B}_{\mathrm{n}}^{\prime}(n=2-5)$ are vinyl- and hydroxyl-terminated PEO oligomer ions which would result from the secondary dissociation of $\mathrm{A}_{\mathrm{n}}{ }^{\alpha}$, according to the same mechanism as described to produce a $B$ fragment from a PEG precursor ion $[16,26]$.

\section{Conclusions}

The microstructure of a living block copolymer could be successfully characterized by tandem mass spectrometry. In spite of the complex chemical structure of the living end-group, unexpectedly simple MS/MS spectra were obtained while maintaining a high level of information. In fact, the high propensity of the $\omega$-end-group to be eliminated, upon activation, as a radical moiety was conferred by the copolymer synthesis technique. The mass of the $\omega$-end-group could thus be reached from this main reaction. The so-formed odd-electron 
ion allowed new fragmentation pathways to proceed. In particular, a complete and fast depolymerization of the PS segment occurred, from which the block nature of the copolymer as well as the size of the PS block could be confirmed. This depolymerization process produced a cationized PEO homopolymer, which size and endgroups could be reached from its $\mathrm{m} / \mathrm{z}$ value. All results presented here are consistent with data recently reported for PS homopolymers, which show that if a labile substituent is at a chain end, this substituent is easily eliminated by homolytic bond cleavage and subsequent depolymerization coupled with backbiting is observed [42]. In case of unknown PEO-b-PS copolymers, characterization of the PEO side would require $\mathrm{MS}^{3}$ experiments to be performed since PEO specific dissociations did not compete effectively with homolytic mechanisms demonstrated for the PS block. An additional dissociation route was also shown to provide structural information about the block junction, allowing to confirm the structure of the alkoxyamine initially used in the living polymerization process.

\section{Acknowledgments}

The authors acknowledge support for this work by the French Research Agency (ANR-06-JCJC-0112). LC acknowledges support from Spectropole, the Analytical Facility of Aix-Marseille University, by allowing a special access to the instruments purchased with European Funding (FEDER OBJ2142-3341). T.N.T. Phan acknowledges Arkema for kindly supplying the MAMA-SG1 alkoxyamine.

\section{References}

1. Park, C.; Yoon, J.; Thomas, E. L. Enabling Nanotechnology with Self Assembled Block Copolymer Patterns. Polymer 2003, 44, 6725-6760.

2. Hamley, I. W. The Physics of Block Copolymers; Oxford University Press: Oxford, 1998

3. Hadjichristidis, N.; Pispas, S.; Floudas, G. A. Block Copolymers: Synthetic Strategies, Physical Properties, and Applications; Wiley Interscience: New York, 2003.

4. Spontak, R. J.; Patel, N. P. Phase Behaviour of Block Copolymer Blends. In Developments in Block Copolymer Science and Technology, Hamley, IW, Ed.; Wiley: New York, 2004; pp. 159-212.

5. Tirelli, N.; Lutolf, M. P.; Napoli, A.; Hubbell, J. A. Poly(Ethylene Glycol) Block Copolymers. Rev. Mol. Biotechnol. 2002, 90, 3-15.

6. Dixit, S. G.; Mahadeshwar, A. R.; Haram, S. K. Some Aspects of the Role of Surfactants in the Formation of Nanoparticles. Colloids Surf. A 1998, 133, 69-75.

7. Sheiko, S. S. Imaging of Polymers Using Scanning Force Microscopy: From Superstructures to Individual Molecules. In. New Developments in Polymer Analytics I, Schmidt M., Ed.; Springer: Berlin, Germany, 2000; pp 61-174.

8. Sun, Z. C.; Gutmann, J. S. Synthesis of TiO2 Nanoparticles in Ultrathin Block Copolymer Films-an Integral Geometry Study. Physica A 2004, 339, 80-85.

9. Bloch, E.; Phan, T.; Bertin. D.; Llewellyn, P.; Hornebecq, V. Direct Synthesis of Mesoporous Silica Presenting Large and Tunable Pores Using BAB Triblock Copolymers: Influence of Each Copolymer Block on the Porous Structure. Microporous Mesoporous Mater. DOI: 10.1016/ j.micromeso. 2007.10.051.

10. Singh, M.; Odusanya, O. Wilmes, G. M. Eitouni, H. B. Gomez, E. D. Patel, A. J.; Chen, V. L.; Park, M. J.; Fragouli, P.; Iatrou, H.; Hadjichristidis, N.; Cookson, D.; Balsara, N. P. Effect of Molecular Weight on the Mechanical and Electrical Properties of Block Copolymer Electrolytes. Macromolecules 2007, 40, 4578-4585.

11. Matyjaszewski, K. Controlled/Living Radical Polymerization; American Chemical Society: Washington DC, 2000; Vol. Series 786.

12. Montaudo, M. S. Mass Spectra of Copolymers. Mass Spectrom. Rev. 2002, $21,108-144$

13. Koster, S.; Duursma, M. C.; Boon, J. J.; Nielen, M. W. F.; de Koster, C. G.; Heeren, R. M. A. Structural Analysis of Synthetic Homo- and Copoly- esters by Electrospray Ionization on a Fourier Transform Ion Cyclotron Resonance Mass Spectrometer. I. Mass Spectrom. 2000, 35, 739-748.

14. Baker, E. S.; Gidden, J.; Simonsick, W. J.; Grady, M. C.; Bowers, M. T. Sequence Dependent Conformations of Glycidyl Methacrylate/Butyl Methacrylate Copolymers in the Gas Phase. Int. J. Mass Spectrom. 2004, 238, 279-286.

15. Haken, J. K. Pyrolysis Gas Chromatography of Synthetic Polymers-a Bibliography. J. Chromatogr. A 1998, 825, 171-187.

16. Lattimer, R. P. Tandem Mass-Spectrometry of Poly(Ethylene Glycol) Lithium-Attachment Ions. J. Am. Soc. Mass Spectrom. 1994, 5, 1072-1080.

17. Przybilla, L.; Francke, V.; Rader, H. J.; Mullen, K. Block Length Determination of a Poly(Ethylene Oxide)-b-Poly(p-Phenylene Ethynylene) Diblock Copolymer by Means of MALDI-TOF Mass Spectrometry Combined with Fragment-Ion Analysis. Macromolecules 2001, 34, 4401-4405.

18. Cerda, B. A.; Horn, D. M.; Breuker, K.; McLafferty, F. W. Sequencing of Specific Copolymer Oligomers by Electron-Capture-Dissociation Mass Spectrometry. J. Am. Chem. Soc. 2002, 124, 9287-9291.

19. Jackson, A. T.; Scrivens, J. H.; Williams, J. P.; Baker, E. S.; Gidden, J.; Bowers, M. T. Microstructural and Conformational Studies of Polyether Copolymers. Int. J. Mass Spectrom. 2004, 238, 287-297.

20. Terrier, P.; Buchmann, W.; Desmazieres, B.; Tortajada, J. Block Lengths and Block Sequence of Linear Triblock and Glycerol Derivative Diblock Copolyethers by Electrospray Ionization-Collision-Induced Dissociation Mass Spectrometry. Anal. Chem. 2006, 78, 1801-1806.

21. Adamus, G.; Sikorska, W.; Kowalczuk, M.; Montaudo, M.; Scandola, M. Sequence Distribution and Fragmentation Studies of Bacterial Copolyester Macromolecules: Characterization of PHBV Macroinitiator by Electrospray Ion-Trap Multistage Mass Spectrometry. Macromolecules 2000, 33, 5797-5802.

22. Arnould, M. A.; Wesdemiotis, C.; Geiger, R. J.; Park, M. E.; Buehner, R. W.; Vanderorst, D. Structural Characterization of Polyester Copolymers by MALDI Mass Spectrometry. Prog. Org. Coat. 2002, 45, 305-312.

23. Adamus, G.; Sikorska, W.; Kowalczuk, M.; Noda, I.; Satkowski, M. M. Electrospray Ion-Trap Multistage Mass Spectrometry for Characterization of Co-Monomer Compositional Distribution of Bacterial Poly(3Hydroxybutyrate-co-3-Hydroxyhexanoate) at the Molecular Level. Rapid Commun. Mass Spectrom. 2003, 17, 2260-2266.

24. Adamus, G.; Montaudo, M. S.; Montaudo, G.; Kowalczuk, M. Molecular Architecture of Poly(R,S)-3-Hydroxybutyrate-co-6-Hydroxyhexanoate and $\operatorname{Poly}(\mathrm{R}, \mathrm{S})-3$-Hydroxybutyrate-co-(R,S)-2-Hydroxyhexanoate Oligomers Investigated by Electrospray Ionization Ion-Trap Multistage Mass Spectrometry. Rapid Commun. Mass Spectrom. 2004, 18, 1436-1446.

25. Hawker, C. J.; Bosman, A. W.; Harth, E. New Polymer Synthesis by Nitroxide Mediated Living Radical Polymerizations. Chem. Rev. 2001, 101, 3661-3688.

26. Lattimer, R. P. Tandem Mass-Spectrometry of Lithium-Attachment Ions from Polyglycols. J. Am. Soc. Mass Spectrom. 1992, 3, 225-234.

27. Jackson, A. T.; Yates, H. T.; Scrivens, J. H.; Critchley, G.; Brown, J. Green, M. R.; Bateman, R. H. The Application of Matrix-Assisted Laser Desorption/Ionization Combined with Collision-Induced Dissociation to the Analysis of Synthetic Polymers. Rapid Commun. Mass Spectrom. 1996, 10, 1668-1674.

28. Bottrill, A. R.; Giannakopulos, A. E.; Waterson, C.; Haddleton, D. M Lee, K. S.; Derrick, P. J. Determination of End-Groups of Synthetic Polymers by Matrix-Assisted Laser Desorption/Ionization: HighEnergy Collision-Induced Dissociation. Anal. Chem. 1999, 71, 3637-3641.

29. Botrill, A. R.; Giannakopulos, A. E.; Millichope, A.; Lee, K. S.; Derrick P. J. Combination of Time-of-Flight Mass Analyzers with MagneticSector Instruments: In-Line and Perpendicular Arrangements. Applications to Poly(Ethylene Glycol) with Long-Chain End-Groups. Eur. J. Mass Spectrom. 2000, 6, 225-232.

30. Hoteling, A. J.; Kawaoka, K.; Goodberlet, M. C.; Yu, W. M.; Owens, K. G. Optimization of Matrix-Assisted Laser Desorption/Ionization Timeof-Flight Collision-Induced Dissociation Using Poly(Ethylene Glycol). Rapid Commun. Mass Spectrom. 2003, 17, 1671-1676.

31. Okuno, S.; Kiuchi, M.; Arakawa, R. Structural Characterization of Polyethers Using Matrix-Assisted Laser Desorption/Ionization Quadrupole Ion Trap Time-of-Flight Mass Spectrometry. Eur. J. Mass Spectrom. 2006, 12, 181-187.

32. Jackson, A. T.; Green, M. R.; Bateman, R. H. Generation of End-Group Information from Polyethers by Matrix-Assisted Laser Desorption/ Ionization Collision-Induced Dissociation Mass Spectrometry. Rapid Commun. Mass Spectrom. 2006, 20, 3542-3550.

33. Chen, R.; Li, L. Lithium and Transition Metal Ions Enable Low Energy Collision-Induced Dissociation of Polyglycols in Electrospray Ionization Mass Spectrometry. J. Am. Soc. Mass Spectrom. 2001, 12, 832-839.

34. Chen, R.; Yu, X. L.; Li, L. Characterization of Poly(Ethylene Glycol) Esters Using Low Energy Collision-Induced Dissociation in Electrospray Ionization Mass Spectrometry. J. Am. Soc. Mass Spectrom. 2002, 13, 888-897.

35. Girod, M.; Carissan, Y.; Humbel, S.; Charles, L. Tandem Mass Spectrometry of Doubly Charged Poly(Ethylene Oxide) Oligomers Produced by Electrospray Ionization. Int. J. Mass Spectrom. 2008, 272, 1-11.

36. Jackson, A. T.; Williams, J. P.; Scrivens, J. H. Desorption Electrospray Ionization Mass Spectrometry and Tandem Mass Spectrometry of Low Molecular Weight Synthetic Polymers. Rapid Commun. Mass Spectrom. 2006, 20, 2717-2727. 
37. Jackson, A. T.; Yates, H. T.; Scrivens, J. H.; Green, M. R.; Bateman, R. H. Matrix-Assisted Laser Desorption/Ionization-Collision Induced Dissociation of Poly(styrene). J. Am. Soc. Mass Spectrom. 1998, 9, 269-274.

38. Jackson, A. T.; Bunn, A.; Hutchings, L. R.; Kiff, F. T.; Richards, R. W.; Williams, J.; Green, M. R.; Bateman, R. H. The Generation of End-Group Information from Poly(Styrene)s by Means of Matrix-Assisted Laser Desorption/Ionization-Collision Induced Dissociation. Polymer 2000, 41, 7437-7450.

39. Hoteling, A. J.; Owens, K. G. Improved PSD and CID on a MALDI TOF MS. J. Am. Soc. Mass Spectrom. 2004, 15, 523-535.

40. Gies, A. P.; Vergne, M. J.; Orndorff, R. L.; Hercules, D. M. MALDI-TOF/ TOF CID Study of Polystyrene Fragmentation Reactions. Macromolecules 2007, 40, 7493-7504.

41. Polce, M. J.; Ocampo, M.; Quirk, R. P.; Wesdemiotis, C. Tandem Mass Spectrometry Characteristics of Silver-Cationized Polystyrenes: Backbone Degradation Via Free Radical Chemistry. Anal. Chem. 2008, 80, 347-354.

42. Polce, M. J.; Ocampo, M.; Quirk, R. P.; Leigh, A. M.; Wesdemiotis, C. Tandem Mass Spectrometry Characteristics of Silver-Cationized Polystyrenes: Internal Energy, Size, and Chain End Versus Backbone Substituent Effects. Anal. Chem. 2008, 80, 355-362.

43. Pastor, S. J.; Wilkins, C. L. Sustained Off-Resonance Irradiation and Collision-Induced Dissociation for Structural Analysis of Polymers by MALDI-FTMS. Int. J. Mass Spectrom. 1998, 175, 81-92.

44. Couturier, J. L.; Guerret, O.; Bertin, D.; Gigmes, D.; Marque, S.; Tordo, P.; Chauvin, F.; Dufils, P. E. Alkoxyamine Originating from $\beta$-Phosphorylated Nitroxides and Use of Thereof in Radical Polymerization. WO2004/014926, 2004.

45. Fischer, H. The Persistent Radical Effect: A Principle for Selective Radical Reactions and Living Radical Polymerizations. Chem. Rev. 2001, $101,3581-3610$.
46. Selby, T. L.; Wesdemiotis, C.; Lattimer, R. P. Dissociation Characteristics of $\mathrm{M}+\mathrm{X}(+)$ Ions $(\mathrm{X}=\mathrm{H}, \mathrm{Li}, \mathrm{K})$ from Linear and Cyclic Polyglycols. J. Am. Soc. Mass Spectrom. 1994, 5, 1081-1092.

47. Iavarone, A. T.; Williams, E. R. Supercharging in Electrospray Ionization: Effects on Signal and Charge. Int. J. Mass Spectrom. 2002, $219,63-72$.

48. Karni, M.; Mandelbaum, A. The Even-Electron Rule. Org. Mass Spectrom. 1980, 15, 53-64.

49. Thurman, E. M.; Ferrer, I.; Pozo, O. J.; Sancho, J. V.; Hernandez, F. The Even-Electron Rule in Electrospray Mass Spectra of Pesticides. Rapid Commun. Mass Spectrom. 2007, 21, 3855-3868.

50. Vonhelden, G.; Wyttenbach, T.; Bowers, M. T. Inclusion of a MALDI Ion-Source in the Ion Chromatography Technique-Conformational Information on Polymer and Biomolecular ions. Int. J. Mass Spectrom. Ion Processes 1995, 146, 349-364.

51. Wu, J. L.; Polce, M. J.; Wesdemiotis, C. Unimolecular Chemistry of Li+and Na+-Coordinated Polyglycol Radicals, a New Cass of Distonic Radical Cations. J. Am. Chem. Soc. 2000, 122, 12786-12794.

52. Vonhelden, G.; Wyttenbach, T.; Bowers, M. T. Conformation of Macromolecules in the Gas Phase-Use of Matrix-Assisted LaserDesorption Methods in Ion Chromatography. Science 1995, 267, 1483-1485.

53. Lehrle, R. S.; Pattenden, C. S. Intramolecular Hydrogen Transfer in Thermal Degradation: Comments on the Size Distribution of the Backbite Rings. Polym. Degrad. Stab. 1999, 63, 153-158.

54. Moscatelli, D. Cavallotti, C. Morbidelli, M. Prediction of Molecular Weight Distributions Based on Ab Initio Calculations: Application to the High Temperature Styrene Polymerization. Macromolecules 2006, 39, 9641-9653. 